\title{
Tobacco-Smoking, Alcohol-Drinking, and Betel-Quid-Chewing Behaviors: Development and Use of a Web-Based Survey System
}

Kuo-Yao Hsu ${ }^{1,2}$, MD; Yun-Fang Tsai ${ }^{3,4,5}, \mathrm{RN}$, PhD; Chu-Ching Huang ${ }^{6}$, PhD; Wen-Ling Yeh ${ }^{2,7}$, MD; Kai-Ping Chang ${ }^{2,8}$, MD, PhD; Chen-Chun Lin ${ }^{9}$, MD; Ching-Yen Chen ${ }^{2,5}$, MD; Hsiu-Lan Lee ${ }^{3,10}$, RN, MS

${ }^{1}$ Division of Orthopedic Sports Medicine, Department of Orthopaedic Surgery, Chang Gung Memorial Hospital at Linkou, Tao-Yuan, Taiwan

${ }^{2}$ College of Medicine, Chang Gung University, Tao-Yuan, Taiwan

${ }^{3}$ School of Nursing, College of Medicine, Chang Gung University, Tao-Yuan, Taiwan

${ }^{4}$ Department of Nursing, Chang Gung University of Science and Technology, Tao-Yuan, Taiwan

${ }^{5}$ Department of Psychiatry, Chang Gung Memorial Hospital at Keelung, Keelung, Taiwan

${ }^{6}$ Division of Natural Science, Center for General Education, Chang Gung University, Tao-Yuan, Taiwan

${ }^{7}$ Department of Orthopedics, Chang Gung Memorial Hospital at Linkou, Tao-Yuan, Taiwan

${ }^{8}$ Division of Head \& Neck Surgery, Department of Otolaryngology, Chang Gung Memorial Hospital, Tao-Yuan, Taiwan

${ }^{9}$ Department of Hepato-Gastroenterology, Chang Gung Memorial Hospital at Linkou, Tao-Yuan, Taiwan

${ }^{10}$ Department of Nursing, Chang Gung Memorial Hospital at Linkou, Tao-Yuan, Taiwan

\section{Corresponding Author:}

Yun-Fang Tsai, RN, PhD

School of Nursing

College of Medicine

Chang Gung University

259, Wen-Hwa 1st Road

Tao-Yuan, 333

Taiwan

Phone: 88632118800 ext 3204

Fax: 88632118868

Email: yftsai@mail.cgu.edu.tw

\section{Abstract}

Background: Smoking tobacco, drinking alcohol, and chewing betel quid are health-risk behaviors for several diseases, such as cancer, cardiovascular disease, and diabetes, with severe impacts on health. However, health care providers often have limited time to assess clients' behaviors regarding smoking tobacco, drinking alcohol, and chewing betel quid and intervene, if needed.

Objective: The objective of this study was to develop a Web-based survey system; determine the rates of tobacco-smoking, alcohol-drinking, and betel-quid-chewing behaviors; and estimate the efficiency of the system (time to complete the survey).

Methods: Patients and their family members or friends were recruited from gastrointestinal medical-surgical, otolaryngology, orthopedics, and rehabilitation clinics or wards at a medical center in northern Taiwan. Data for this descriptive, cross-sectional study were extracted from a large series of research studies. A Web-based survey system was developed using a Linux, Apache, MySQL, PHP stack solution. The Web survey was set up to include four questionnaires: the Chinese-version Fagerstrom Tolerance Questionnaire, the Chinese-version Alcohol Use Disorders Identification Test, the Betel Nut Dependency Scale, and a sociodemographic form with several chronic diseases. After the participants completed the survey, the system automatically calculated their score, categorized their risk level for each behavior, and immediately presented and explained their results. The system also recorded the time each participant took to complete the survey.

Results: Of 782 patient participants, $29.6 \%$ were addicted to nicotine, $13.3 \%$ were hazardous, harmful, or dependent alcohol drinkers, and $1.5 \%$ were dependent on chewing betel quid. Of 425 family or friend participants, $19.8 \%$ were addicted to nicotine, $5.6 \%$ were hazardous, harmful, or dependent alcohol drinkers, and $0.9 \%$ were dependent on chewing betel quid. Regarding the mean time to complete the survey, patients took 7.9 minutes (SD 3.0; range 3-20) and family members or friends took 7.7 minutes (SD 2.8; range 3-18). Most of the participants completed the survey within 5-10 minutes.

Conclusions: The Web-based survey was easy to self-administer. Health care providers can use this Web-based survey system to save time in assessing these risk behaviors in clinical settings. All smokers had mild-to-severe nicotine addiction, and 5.6\%-12.3\% 
of patients and their family members or friends were at risk of alcohol dependence. Considering that these three behaviors, particularly in combination, dramatically increase the risk of esophageal cancer, appropriate and convenient interventions are necessary for preserving public health in Taiwan.

(JMIR Mhealth Uhealth 2018;6(6):e142) doi: 10.2196/mhealth.9783

\section{KEYWORDS}

tobacco smoking; alcohol drinking; betel-quid chewing; Web-based survey system

\section{Introduction}

Tobacco smoking has devastating global health, social, environmental, and economic consequences [1]. Each year, $>7$ million people worldwide die from tobacco use [2], with over $80 \%$ of deaths occurring in low- or middle-income countries [3]. On average, tobacco users lose 15 years of life [4]. Up to $50 \%$ of all tobacco users die of tobacco-related causes, including heart disease, cancer, diabetes, and lung disease [5]. Illnesses caused by tobacco use also contribute to poverty by increasing health care spending for individuals and families [1]. In addition, tobacco waste contains over 7000 toxic chemicals, including human carcinogens. Tobacco smoke emissions also contribute thousands of tons of human carcinogens, toxicants, and greenhouse gases to the environment [1]. Moreover, tobacco use imposes a substantial economic burden globally. Smoking-attributable costs, both direct (eg, the cost incurred by the utilization of health care services) and indirect (eg, any additional cost incurred as a result of the utilization of health care services), are estimated to be US \$ 1400 billion or $1.8 \%$ of the global gross domestic product [6].

Excessive alcohol use has been associated with a large variety of health, social, and legal problems [7]. In 2012, approximately 3.3 million deaths, or $5.9 \%$ of all deaths worldwide, were attributable to alcohol consumption [8]. Alcohol consumption is associated with an increased risk of over 200 diseases and injuries [8]; it has also been associated with mental and behavioral disorders, including alcohol dependence, liver cirrhosis, some cancers, and cardiovascular diseases, as well as injuries from violence and traffic accidents [8].

Betel-quid chewing is a popular habit in south and Southeast Asia [9]; it has a carcinogenic effect and is associated with obesity, hypertriglyceridemia, hyperglycemia, metabolic syndrome, cardiovascular disease, hepatic dysfunction, liver cirrhosis, and liver cancer [10-12].

In countries such as Taiwan, where people commonly smoke, drink alcohol, and chew betel quid, esophageal cancer is prevalent [13]. Indeed, the concurrent use of alcohol and tobacco leads to a higher risk of esophageal cancer (odds ratio [OR] 8), and the addition of betel-quid chewing can increase the odds ratio to 195.6 (95\% CI 64.0-894.2) [14,15].

In Taiwan, the smoking rate of adults dropped from $32.5 \%$ in 1990 to $15.3 \%$ in 2016 , but there were still 3.13 million tobacco smokers (individuals who smoked $>100$ cigarettes to date and had smoked in the last 30 days) [16]. Alcohol, which is legally accessible in Taiwan, plays an important role in Chinese culture as it is viewed as an acceptable drink to relieve stress and enhance social interaction [17]. Consequently, drinking problems are easily ignored. In Taiwan's general hospitals, the prevalence of patients' alcohol-drinking problems (Alcohol Use Disorders Identification Test, AUDIT, score $\geq 8$ ) ranges from $5.7 \%$ to $19.2 \%$ due to different settings (wards versus clinics) selected [18,19]. In addition, chewing betel quid is a part of traditional Chinese culture, and it is often offered during many social occasions in Taiwan [20]. A national survey conducted in the last 6 months of 2013 found that the rates of adult smoking (individuals smoking >100 cigarettes) and alcohol drinking (individuals drinking alcohol liquor not included in cooking) were $22.6 \%$ and $39.2 \%$, respectively; in both the previous year and previous 6 months, the rate of chewing betel quid was $6.4 \%$ [21]. These statistics indicate that smoking, drinking alcohol, and chewing betel quid are troubling health-risk behavior indicators in Taiwan.

Considering that individuals who smoke tobacco, drink alcohol, and chew betel quid are likely to suffer adverse effects on their health (eg, cancer, cardiovascular disease, and diabetes), they will need to seek health care. Thus, health care providers are in a unique position to both identify and treat patients with these unhealthy behaviors. However, limited time often presents providers with a barrier to implement both appropriate assessment and intervention strategies [22,23]. This barrier may be overcome by using a Web-based system. Indeed, Web-based systems have been found to arouse participants' interests about their own health, maintain privacy, increase reasonable response rates, and save costs [24]. Unfortunately, most Web-based systems are available only for alcohol screening and interventions [25], and no Web-based system combines tobacco smoking, alcohol drinking, and betel-quid chewing. To address this knowledge gap, we undertook this study to develop a Web-based survey system and determine the rates of tobacco-smoking, alcohol-drinking, and betel-quid-chewing behaviors in patients and their family members or friends recruited from a medical center in Taiwan. We also estimated the efficiency of this system by calculating the time to complete the survey.

\section{Methods}

\section{Design}

This descriptive cross-sectional study was a part of an extensive research series to promote healthy lifestyle behaviors for the general population. Data were collected using a Web-based survey from 2015 to 2016 .

\section{Sample and Setting}

The sample was recruited by a trained research assistant (RA) from the waiting areas of gastrointestinal medical-surgical, otolaryngology, orthopedics, and rehabilitation clinics/wards 
at a medical center in northern Taiwan. These clinics and wards were chosen because most patients with alcohol or smoking problems in Taiwan are seen here [26]. Patients were included if they met the following criteria: (1) $\geq 20$ years old, (2) outpatients or inpatients in the above clinics or wards, (3) had mobile phones or email access, and (4) able to read Chinese. Similar inclusion criteria were used for patients' family members, partners, and friends.

Patients were approached by the RA who told them that our research team was interested in developing a Web-based substance-use intervention system and would like their participation for at least 20 minutes to help develop the new system. After obtaining written consent from patients, family members, and friends to participate, the RA screened each one for both inclusion and exclusion criteria. Of the 1400 patients approached, only 1210 agreed to participate. Those who refused to participate gave lack of time as the main reason for refusing. Of the patients who agreed to participate, 3 did not meet the inclusion criteria; thus, 1207 completed the survey. No participants dropped out of this study.

\section{The Web-Based Survey System}

The system was built using a Linux, Apache, MySQL, PHP stack solution. The Linux operation system was hosted on a lightweight Dell server (with two Intel 3.0-GHz CPU processors and $8 \mathrm{G}$ RAM) to provide the survey via the internet. The Apache web server system runs on the Dell server. To address the gap of no appropriate software packages available to set up a Web-based survey system, we developed our system from scratch using PHP: hypertext preprocessor (PHP) language, a well-known, reliable server-site technology. Within the survey system, we set up four questionnaires or scales: the Chinese-version Fagerstrom Tolerance Questionnaire (C-FTQ) [27], the Chinese-version AUDIT (C-AUDIT) [26], the Betel Nut Dependency Scale (BNDS) [28], and a sociodemographic form. The C-FTQ was chosen because it has been used as a screening tool for tobacco control by Taiwan's Health Promotion Administration, Ministry of Health and Welfare [27]. The C-AUDIT was translated and validated by our research team [26] from the World Health Organization (WHO)-developed AUDIT, a commonly used and widely translated tool for screening alcohol problems [29]. The BNDS, which is the only available screening tool for betel-nut dependence in the general population of Taiwan, has undergone comprehensive psychometric testing [28]. After participants completed the survey, their scores were automatically calculated, their risk behaviors were categorized (from no risk to high risk, depending on each questionnaire's definitions; see next section), and their results were immediately presented with explanations. The system also recorded the time required for each participant to complete the survey.

Before using the Web-based survey system in clinical settings, we tested its stability and accuracy. Testing involved the following: setting up an account and password to access the survey; answering questions; and checking scores, categories, and explanations. A technician and RAs in our lab tested the system more than 10,000 times over 3 months. In addition, we retrieved all data, entered it into statistical software, and regularly calculated the total score for each tool to ensure the accuracy of the process. No mistakes were detected.

\section{Study Variables}

These scales were used to collect data on participants' physical dependence on nicotine, alcohol drinking-related behaviors, betel-quid dependency, and sociodemographic characteristics plus several chronic diseases.

Physical dependence on nicotine in the previous year was measured using the 7-item C-FTQ. The first item asks, "Did you smoke in the past year?" If the participant answers "no," he or she skips the remaining 6 items and the score is 0 . If the participant answers "yes" to the first item, he/she answers the remaining items. The total C-FTQ score represents the sum of items 2-7; possible score range $0-10$. A score of 0 indicates no smoking behavior. Summed scores $\leq 3$ indicate mild nicotine addiction, 4-6 indicates moderate addiction, and 7-10 indicates high addiction [27]. The validity and reliability of the FTQ [30,31] and C-FTQ [32] were acceptable. The internal consistency of the C-FTQ in this study was 0.76 .

Alcohol drinking-related behaviors in the previous year were measured using the 10-item C-AUDIT. Each item was scored on a 4-point Likert scale from 0 to 1 , with total scores ranging from 0 to 40 . Scores 0-7 indicate low-risk drinking, 8-15 indicate hazardous drinking, 16-19 indicate harmful drinking, and $\geq 20$ indicate dependence in drinking [29]. The validity and reliability of the AUDIT [29] and C-AUDIT [26] were acceptable. The internal consistency of the C-AUDIT in this study was 0.83 .

Betel-quid dependency in the previous year was measured using the 11-item BNDS. Items were scored on a 4-point Likert scale ( $1=$ totally agree, $2=$ agree, $3=$ disagree, $4=$ totally disagree $)$. Item scores were summed for a total score, with a possible range of $11-44$; scores $\geq 24$ indicate a tendency toward betel-quid dependency [28]. The validity and reliability of the BNDS were acceptable [28]. The internal consistency of the BNDS in this study was 0.96 .

Sociodemographic characteristics (age, gender, education level, marital status, number of children) were measured using a sociodemographic form. Chronic illnesses (arthritis, cancer, cardiovascular disease, cataract, diabetes, digestive system disease, epilepsy, gout, hyperlipidemia, hypertension, kidney disease, liver disease, stroke, urinary tract disease) were measured using a chronic illness checklist.

\section{Data Collection}

After screening participants for study criteria, the RA provided each one a sealed envelope containing a login account and password. The RA also provided written instructions for accessing the web system. The participants read these instructions by themselves. The RA then helped the participants find a seat in the waiting area, gave them a laptop computer, and let them complete the survey alone. The participants connected to the internet via the participating hospital's free $\mathrm{Wi}-\mathrm{Fi}$. If the free $\mathrm{Wi}-\mathrm{Fi}$ was not accessible in the waiting area, the participants connected to a $4 \mathrm{G}$ wireless network paid by researchers. After the participants finished the online survey, it automatically provided their score on each questionnaire with 
explanations of the scores. The system also reminded the participants to discuss any health concerns with their health care providers. After the participants finished the survey, they caught the RA's attention to return the laptop computer. The RA stayed in the waiting area in case the participants needed any help. In addition, the RA provided information to the participants about tobacco smoking, alcohol drinking, and betel-quid chewing, if they needed it, after completing the survey.

\section{Ethical Considerations}

After the institutional review board of Chang Gung Memorial Hospital approved the study, the RA approached patients, their family members, or friends in the wards or clinic waiting areas. The RA described the study purpose and procedure, the required time commitment, confidentiality, and participants' rights not to participate or to withdraw from the study at any time and obtained their written consent to participate. The participants received a small gift (approximately US \$3) for their participation.

\section{Data Analysis}

Sociodemographic and questionnaire data were analyzed by descriptive statistics (mean, standard deviation, and frequency [percentage]) using SPSS, version 22.

\section{Results}

The average age of the 782 patients who participated in this study was 35.9 years (SD 11.9; range 20-83). Most of the patients were male $(533 / 782,68.2 \%)$, had graduated from a college or university $(435 / 782,55.6 \%)$, were single $(408 / 782$, $52.2 \%$ ), and sought treatment in orthopedics clinics or wards (492/782, 62.9\%). For details, see Table 1. Patients' top three chronic diseases were liver diseases (77/782, 9.8\%), hypertension $(71 / 782,9.1 \%)$, and diabetes $(31 / 782,4.0 \%)$ (see Table 2 for details).

The 425 patients' family members and friends in our sample were on average 35.3 years old (SD 10.8; range 20-79). Most of them were male $(216 / 425,50.8 \%)$ and had graduated from a college or university $(250 / 425,58.8 \%)$. Approximately half of them were single $(207 / 425,48.7 \%)$ or married $(206 / 425$, $48.5 \%$ ). For details, see Table 1. For these family members and friends, the top three common chronic diseases were liver diseases $(19 / 425,4.5 \%)$, hypertension $(19 / 425,4.5 \%)$, and diabetes $(9 / 425,2.1 \%)$ (see Table 2 for details).

Table 1. Participants' demographic characteristics.

\begin{tabular}{|c|c|c|}
\hline Variable & Patients & Family members and friends \\
\hline \multicolumn{3}{|l|}{ Gender, n (\%) } \\
\hline Male & $533(68.2)$ & $216(50.8)$ \\
\hline Female & $249(31.7)$ & $209(49.2)$ \\
\hline Age (years), mean (SD) & $35.9(11.9)$ & $35.3(10.8)$ \\
\hline \multicolumn{3}{|l|}{ Visit clinic or ward, n (\%) } \\
\hline Orthopedics & $492(62.7)$ & $232(54.5)$ \\
\hline Otolaryngology & $188(23.9)$ & $114(26.8)$ \\
\hline Gastroenterology & 99 (12.6) & 75 (17.6) \\
\hline Rehabilitation medicine & $3(0.4)$ & $4(0.9)$ \\
\hline \multicolumn{3}{|l|}{ Education level, n (\%) } \\
\hline Illiterate & $4(0.5)$ & $4(0.9)$ \\
\hline Primary school & $20(2.6)$ & $2(0.5)$ \\
\hline Junior high school & $46(5.9)$ & $18(4.2)$ \\
\hline Senior high school & $165(21.1)$ & $113(26.6)$ \\
\hline College or university & $435(55.6)$ & $250(58.8)$ \\
\hline Master's degree or above & $112(14.3)$ & $38(8.9)$ \\
\hline \multicolumn{3}{|l|}{ Marital status, n (\%) } \\
\hline Single & $408(52.2)$ & $207(48.7)$ \\
\hline Married & $354(45.3)$ & $206(48.5)$ \\
\hline Divorced & $17(2.2)$ & $11(2.6)$ \\
\hline Widowed & $3(0.4)$ & $1(0.2)$ \\
\hline Number of children, mean (SD) & $0.9(1.2)$ & $0.9(1.2)$ \\
\hline
\end{tabular}


Table 2. Participants' chronic illnesses.

\begin{tabular}{lll}
\hline Illness & Patients, $\mathrm{n}(\%)$ & Family members and friends, $\mathrm{n}(\%)$ \\
\hline Liver disease & $77(9.8)$ & $19(4.5)$ \\
Hypertension & $71(9.1)$ & $9(2.1)$ \\
Diabetes & $31(4.0)$ & $2(0.5)$ \\
Arthritis & $29(3.7)$ & $1(0.2)$ \\
Cancer & $23(2.9)$ & $8(1.9)$ \\
Digestive system disease & $15(1.9)$ & $7(1.6)$ \\
Cardiovascular disease & $15(1.9)$ & $5(1.2)$ \\
Hyperlipidemia & $8(1.0)$ & $4(0.9)$ \\
Gout & $8(1.0)$ & $2(0.5)$ \\
Urinary tract disease & $7(0.9)$ & $2(0.5)$ \\
Kidney disease & $6(0.8)$ & $0(0.0)$ \\
Cataract & $2(0.3)$ & $1(0.2)$ \\
Epilepsy & $1(0.1)$ & $0(0.0)$ \\
Stroke & $1(0.1)$ & 0.0 \\
\hline
\end{tabular}

Table 3. Participants' smoking, drinking, and betel-quid-chewing scores.

\begin{tabular}{|c|c|c|}
\hline Variable & Patients & Family members and friends \\
\hline C-FTQ ${ }^{\mathrm{a}}$ score, mean (SD) & $1.1(2.2)$ & $0.7(1.9)$ \\
\hline \multicolumn{3}{|l|}{ C-FTQ addiction level, n (\%) } \\
\hline No addiction & $550(70.3)$ & $341(80.2)$ \\
\hline Mild addiction & $111(14.2)$ & $44(10.4)$ \\
\hline Moderate addiction & $84(10.7)$ & $25(5.9)$ \\
\hline High addiction & $37(4.7)$ & $15(3.5)$ \\
\hline C-AUDIT ${ }^{\mathrm{b}}$ score, mean (SD) & $2.8(4.5)$ & $1.7(3.2)$ \\
\hline \multicolumn{3}{|l|}{ C-AUDIT level, n (\%) } \\
\hline Low-risk drinker & $678(86.7)$ & $401(94.4)$ \\
\hline Hazardous drinker & $78(10.0)$ & $18(4.2)$ \\
\hline Harmful drinker & $18(2.3)$ & $6(1.4)$ \\
\hline Dependent drinker & $8(1.0)$ & $0(0.0)$ \\
\hline $\mathrm{BNDS}^{\mathrm{c}}$, mean $(\mathrm{SD})$ & $11.6(2.9)$ & $11.4(2.6)$ \\
\hline \multicolumn{3}{|l|}{ BNDS level, n (\%) } \\
\hline No potential addiction & $770(98.5)$ & $421(99.1)$ \\
\hline Potential addiction & $12(1.5)$ & $4(0.9)$ \\
\hline
\end{tabular}

${ }^{\mathrm{a} C}$-FTQ: Chinese-version Fagerstrom Tolerance Questionnaire.

${ }^{\mathrm{b}} \mathrm{C}$-AUDIT: Chinese-version Alcohol Use Disorders Identification Test.

${ }^{\mathrm{c}}$ BNDS: Betel Nut Dependency Scale.

Patients' mean C-FTQ, C-AUDIT, and BNDS scores were 1.1 (SD 2.2), 2.8 (SD 4.5), and 11.6 (SD 2.9), respectively. Among patients, $29.7 \%$ (232/782) were mildly to highly addicted to nicotine; $13.3 \%$ (104/782) were hazardous, harmful, or dependent drinkers; and $1.5 \%(12 / 782)$ were betel-quid dependent. Family members' and friends' mean C-FTQ,
C-AUDIT, and BNDS scores were 0.7 (SD 1.9), 1.7 (SD 3.2), and 11.4 (SD 2.6), respectively. Among family members and friends, $19.8 \%(84 / 425)$ were addicted to nicotine, $5.6 \%$ $(24 / 425)$ were hazardous or harmful drinkers, and $0.9 \%(4 / 425)$ were betel-quid dependent. For details, see Table 3. 
Table 4. Participants' smoking, drinking, and betel-quid-chewing behaviors.

\begin{tabular}{lll}
\hline Risk behavior & Patients, $\mathrm{n}(\%)$ & Family members and friends, $\mathrm{n}(\%)$ \\
\hline None & $256(32.7)$ & $179(42.1)$ \\
Smoking only & $35(4.5)$ & $20(4.7)$ \\
Drinking only & $287(36.7)$ & $161(37.9)$ \\
Betel-quid chewing only & $0(0.0)$ & $0(0.0)$ \\
Smoking and drinking & $131(16.8)$ & $44(10.4)$ \\
Smoking and betel-quid chewing & $9(1.2)$ & $4(0.09)$ \\
Drinking and betel-quid chewing & $7(0.09)$ & $1(0.02)$ \\
Smoking and drinking and betel-quid chewing & $57(7.3)$ & $16(3.8)$ \\
\hline
\end{tabular}

Only $32.7 \%$ (256/782) of patients did not smoke, drink alcohol, and chew betel quid in the previous year. Over $60 \%$ (482/782, $61.6 \%$ ) of patients drank alcohol in the past year (including drinking only, smoking and drinking, drinking and betel-quid chewing, and smoking and drinking and betel-quid chewing). Similarly, only $42.1 \%$ (179/425) of family members and friends did not smoke, drink alcohol, and chew betel quid in the previous year. Over $52 \%(222 / 425,52.2 \%)$ of family members and friends drank alcohol in the past year. For details, see Table 4.

Regarding the mean time to complete the survey, patients needed 7.9 minutes (SD 3.0; range 3-20) and family members or friends needed 7.7 minutes (SD 2.8; range 3-18). Most patients completed the survey within 5-10 minutes $(656 / 782,83.9 \%)$, and most family members or friends completed it within 5-10 minutes $(363 / 425,81.7 \%)$.

\section{Discussion}

\section{Web-Based Survey System}

Our Web-based survey system to assess behaviors regarding drinking alcohol, smoking tobacco, and chewing betel quid contributes to the literature on health-risk behaviors by providing a survey that patients can complete easily, quickly, and entirely. Most participants completed it within 5-10 minutes and perceived it as being easy to self-administer. The survey was designed to ensure that the participants could not skip any item, thus avoiding missing data, by requiring that each item be filled in before moving to the next page. Furthermore, our data on the internal consistency of the Web-versions of the C-FTQ, C-AUDIT, and BNDS were all acceptable. Unlike other assessment tools, such as the Kihon checklist [33], which must be administered by health care providers, using this survey can save time for providers to assess these risk behaviors in clinical settings. Moreover, the survey results provide client data for health-promotion strategies on smoking tobacco, drinking alcohol, and chewing betel quid.

Regarding internet access for the online survey, we initially used the participating hospital's new, free Wi-Fi for visitors, but this system was unstable. We did not want to ask the participants to use their own smart phone, if the free Wi-Fi did not work, because they might have worried about increasing their internet service fee and refused to participate in our study. Therefore, we provided a laptop for the participants and allowed them to use either free $\mathrm{Wi}-\mathrm{Fi}$ or a researcher-paid $4 \mathrm{G}$ network to complete the survey. Currently, the hospital's free Wi-Fi system for visitors is stable. Once our research on the Web-based survey and its efficacy is published, we plan to add a quick response (QR) code system to the survey. Patients and family members can use their own smart phone to scan the QR code and fill out the survey. This change will increase the accessibility of the online survey system in clinical settings. After the present Web-based survey system matures, its use may be expanded to include the public setting for assessing health behaviors in the general population.

\section{Smoking, Drinking, and Betel-Quid-Chewing Behaviors}

Approximately $30 \%$ of patients and $20 \%$ of family members and friends smoked in the past year, but all of them were categorized as having mild-to-severe nicotine addiction. These prevalence rates for tobacco smoking are in line with the 2010 WHO global prevalence of $22.1 \%$ [34] but exceed Taiwan's national rate of $15.3 \%$ established by the Adult Smoking Behavior Surveillance System in 2016 [13]. Given that tobacco smoking has a negative impact on health, it is essential to decrease smoking behaviors. To assist governments worldwide in reducing both tobacco demand and use, in 2008, the WHO introduced a package of six evidence-based strategies [34]. These strategies, known as the MPOWER package, include Monitoring tobacco use and prevention policies; Protecting people from tobacco smoke; Offering help to quit tobacco use; Warning about the dangers of tobacco; Enforcing bans on tobacco advertising, promotion, and sponsorship; and Raising taxes on tobacco [34]. Among these strategies, those that could be implemented in clinical settings include establishing smoke-free buildings and grounds, offering smoking-cessation programs, providing warning labels on tobacco packages, and enforcing bans on tobacco promotion.

Among our participants, over $60 \%$ of patients and over $52 \%$ of family members or friends drank alcohol in the past year, and $13.3 \%$ of patients and $5.6 \%$ of family members or friends were categorized as hazardous, harmful, or dependent drinkers. The prevalence for our patient sample is at the low end of the range reported for alcohol-drinking problems in general hospitals in western countries, that is, $12 \%$ to $26 \%$, due to different assessment methods and units selected [35,36]. However, no information is available on studies conducted in western countries for the prevalence of alcohol-drinking problems among 
family members of these patients. Our patient sample's prevalence of hazardous, harmful, or dependent drinkers is consistent with that of patients' alcohol-drinking problems in Taiwan's general hospitals, that is, $5.7 \%$ to $19.2 \%$, depending on the unit selected $[18,19]$. However, our finding on the prevalence of patients' family members'/friends' hazardous/harmful/dependent drinking $(5.6 \%)$ is much lower than that of hazardous alcohol-drinking problems among family members of patients with alcohol-drinking problems in Taiwan (13.3\%) [37]. The difference between the findings of these studies may be because our sample of family members or friends included approximately 25\% friends (105/425). Indeed, individuals with a family history of alcoholism have been linked to a greater risk of developing alcoholism than those without such a history [38].

To manage the drinking behavior of individuals with hazardous and harmful drinking, a brief intervention [18] has proven to be effective in a Taiwanese hospital patient population $[18,22]$. This brief intervention is offered to problem drinkers at four levels, based on their AUDIT score [22]. The first level, for low-risk drinkers, is to provide alcohol education. The second level, for hazardous drinkers, is to give simple advice (including giving feedback, providing information, establishing goals to change drinking behavior, giving advice on drinking limits, reviewing the amount of alcohol in standard drinks, and concluding with encouragement). The third intervention level, for harmful drinkers, is to provide simple advice plus brief counseling and continued monitoring. The fourth level, for dependent drinkers, is to refer them to a specialist for diagnostic evaluation and treatment [22]. This brief intervention should be considered as a strategy to decrease our participants' alcohol drinking behaviors.

The prevalence of betel-quid dependency was low in both patients and family members or friends. Currently, no effective interventions for betel-quid chewing are available. Our findings show that no participants chewed betel quid alone; they only used it in combination with smoking or drinking alcohol. This finding implies that interventions against betel-quid chewing should be combined with antismoking or alcohol-drinking interventions.

\section{Strengths and Limitations}

Our study fills a knowledge gap by both developing and applying a convenient Web-based survey system to assess behaviors regarding smoking tobacco, drinking alcohol, and chewing betel quid. Our results demonstrate that the system is easy to use for both patients and their family members or friends. However, this study had four limitations. First, the study population was a convenient sample recruited from one hospital in northern Taiwan. Second, participants were included only if they had mobile phones or email access. In other words, they had some experience using Web-based systems. Third, participants may have been hindered in expressing whether the survey was difficult when asked in person by the RA. Fourth, we did not follow-up with participants to determine if they had discussed their survey results with their health care providers because this follow-up was beyond the scope of our study. For the same reason, we did not survey physicians regarding both their knowledge of the widely used tobacco-smoking, alcohol-drinking, and betel-quid-chewing scales used in our survey and their readiness to assess their clients for these health-risk behaviors. Further studies may consider using a random sampling strategy; expanding the study criteria to include people naïve to computers, communication, and consumer products; following up with both patients and their health care providers on the application of survey results; and including an item at the end of the survey to ask anonymously about the difficulty in completing the survey.

\section{Conclusions}

Smoking, drinking alcohol, and chewing betel quid are risk behaviors with severe impacts on health. However, health care providers often have little or limited time to evaluate their clients for these risk behaviors. Using our newly developed Web-based survey system can save clinicians' time for assessing patients and offering participants data about their health behaviors. We also found that all smokers had a mild-to-severe nicotine addiction, and both patients and their family members or friends had a high prevalence of drinking alcohol in the past year. Furthermore, $5.6 \%-12.3 \%$ of patients and their family members or friends were at risk of alcohol dependence. Since these three behaviors, particularly in combination, dramatically increase the risk of esophageal cancer, appropriate and convenient interventions are necessary for maintaining public health in Taiwan.

\section{Acknowledgments}

This study was funded by Chang Gung Memorial Hospital (CMRPD3E0181-2, BMRP433) and the Ministry of Science and Technology (MOST 106-2314-B-182-009-MY3).

\section{Authors' Contributions}

KYH assisted with designing the study, collecting and analyzing the data, and writing the manuscript. YFT designed the study, supervised the data collection, analyzed the data, and wrote the manuscript. CCH designed the Web-based survey system, assisted with collecting and analyzing the data, as well as writing the manuscript. WLY, KPC, CCL, CYC, and HLL assisted with collecting and analyzing the data, as well as writing the manuscript.

\section{Conflicts of Interest}

None declared. 


\section{References}

1. World Health Organization. Tobacco Threatens Us All. 2017. URL: http://apps.who.int/iris/bitstream/10665/255561/1/ WHO-NMH-PND-17.2-eng.pdf?ua=1 [accessed 2018-05-20] [WebCite Cache ID 6zYdMeypr]

2. GBD 2015 Risk Factors Collaborators. Global, regional, and national comparative risk assessment of 79 behavioural, environmental and occupational, and metabolic risks or clusters of risks, 1990-2015: a systematic analysis for the Global Burden of Disease Study 2015. Lancet 2016 Oct 08;388(10053):1659-1724 [FREE Full text] [doi:

10.1016/S0140-6736(16)31679-8] [Medline: 27733284]

3. Mathers CD, Loncar D. Projections of global mortality and burden of disease from 2002 to 2030. PLoS Med 2006 Nov;3(11):e442 [FREE Full text] [doi: 10.1371/journal.pmed.0030442] [Medline: 17132052]

4. World Health Organization. WHO Report on the Global Tobacco Epidemic, 2008: the MPOWER Package. Geneva: World Health Organization; 2008.

5. World Health Organization. WHO Global Report: Mortality Attributable to Tobacco. Geneva: World Health Organization; 2012.

6. United States National Cancer Institute, World Health Organization. The Economics of Tobacco and Tobacco Control. National Cancer Institute Tobacco Control Monograph 21. NIH Publication No. 16-CA-8029A. Bethesda; Geneva: United States Department of Health and Human Services, National Institutes of Health, National Cancer Institute; World Health Organization; 2016.

7. World Health Organization. Management of substance abuse. Facts and figures: alcohol. 2009. URL: http://www.who.int/ substance_abuse/facts/alcohol/en/ [accessed 2018-05-20] [WebCite Cache ID 6zYSwSUj2]

8. World Health Organization. Alcohol. 2018. URL: http://www.who.int/en/news-room/fact-sheets/detail/alcohol [accessed 2018-05-20] [WebCite Cache ID 6zYT5wYMr]

9. Bolye P, Levin B. World Cancer Report 2008. Lyon: International Agency for Research on Cancer; 2008.

10. Yen AM, Chen LS, Chiu YH, Boucher BJ, Chen TH. A prospective community-population-registry based cohort study of the association between betel-quid chewing and cardiovascular disease in men in Taiwan (KCIS no. 19). Am J Clin Nutr 2008 Jan;87(1):70-78 [FREE Full text] [Medline: 18175739]

11. Yen AM, Chiu YH, Chen LS, Wu HM, Huang CC, Boucher BJ, et al. A population-based study of the association between betel-quid chewing and the metabolic syndrome in men. Am J Clin Nutr 2006 May;83(5):1153-1160 [FREE Full text] [Medline: 16685060 ]

12. Wu GH, Boucher BJ, Chiu YH, Liao CS, Chen TH. Impact of chewing betel-nut (Areca catechu) on liver cirrhosis and hepatocellular carcinoma: a population-based study from an area with a high prevalence of hepatitis B and C infections. Public Health Nutr 2009 Jan;12(1):129-135. [doi: 10.1017/S1368980008002073] [Medline: 18410705]

13. Chung CS, Lee YC, Wang CP, Ko JY, Wang WL, Wu MS, et al. Secondary Prevention of Esophageal Squamous Cell Carcinoma in Areas Where Smoking, Alcohol, and Betel Quid Chewing are Prevalent. Journal of the Formosan Medical Association 2010 Jun;109(6):408-421. [doi: 10.1016/S0929-6646(10)60072-1]

14. Castellsagué X, Muñoz N, De SE, Victora CG, Castelletto R, Rolón PA, et al. Independent and joint effects of tobacco smoking and alcohol drinking on the risk of esophageal cancer in men and women. Int J Cancer 1999 Aug 27;82(5):657-664 [FREE Full text] [Medline: 10417762]

15. Wu IC, Lu CY, Kuo FC, Tsai SM, Lee KW, Kuo WR, et al. Interaction between cigarette, alcohol and betel nut use on esophageal cancer risk in Taiwan. Eur J Clin Invest 2006 Apr;36(4):236-241. [doi: 10.1111/j.1365-2362.2006.01621.x] [Medline: 16620285]

16. Health Promotion Administration, Ministry of Health and Welfare. Adult Smoking Behavior Surveillance System. URL: http://tobacco.hpa.gov.tw/Show.aspx?MenuId=819 [accessed 2018-05-21] [WebCite Cache ID 6zaJEvtti]

17. Newman I. Cultural aspects of drinking patterns and alcohol controls in China. The Globe (Global Alcohol Policy Alliance, London) 2002;1:18-21 [FREE Full text]

18. Tsai YF, Tsai MC, Lin YP, Chen CY. Brief intervention for problem drinkers in a Chinese population: a randomized controlled trial in a hospital setting. Alcohol Clin Exp Res 2009 Jan;33(1):95-101. [doi: 10.1111/j.1530-0277.2008.00815.x] [Medline: 18945220]

19. Tsai YF, Lin YP, Tsai MC, Weng CE, Chen CY. Hazardous alcohol-drinking problems among a Chinese hospital patient population. J Adv Nurs 2013 Aug;69(8):1819-1828. [doi: 10.1111/jan.12043] [Medline: 23157429]

20. Tsai YF, Wong TKS, Chen SC. Prevalence and related risk factors of areca quid chewing among junior high students in eastern Taiwan. Public Health 2002 Jul;116(4):190-194. [doi: 10.1038/sj.ph.1900862] [Medline: 12087476]

21. National Health Research Institutes \& Health Promotion Administration, Ministry of Health and Welfare. National Health Interview Survey in 2013. URL: http://nhis.nhri.org.tw/2013download.html [accessed 2018-05-20] [WebCite Cache ID 6zYTK6o5E]

22. Babor TF, Higgins-Biddle JC. Brief Intervention for Hazardous and Harmful Drinking: A Manual for Use in Primary Care. Geneva: World Health Organization; 2001.

23. Tsai YF. Nurses' perceived facilitators and barriers to assessing for alcohol use in Taiwan. J Clin Nurs 2009 Jul;18(14):2078-2086. [doi: 10.1111/j.1365-2702.2008.02590.x] [Medline: 19220620] 
24. Walters ST, Hester RK, Chiauzzi E, Miller E. Demon rum: high-tech solutions to an age-old problem. Alcohol Clin Exp Res 2005 Feb;29(2):270-277. [Medline: 15714050]

25. Guillemont J, Cogordan C, Nalpas B, Nguyen-Thanh V, Richard J, Arwidson P. Effectiveness of a web-based intervention to reduce alcohol consumption among French hazardous drinkers: a randomized controlled trial. Health Educ Res 2017 Aug 01;32(4):332-342. [doi: 10.1093/her/cyx052] [Medline: 28854571]

26. Tsai MC, Tsai YF, Chen CY, Liu CY. Alcohol Use Disorders Identification Test (AUDIT): establishment of cut-off scores in a hospitalized Chinese population. Alcohol Clin Exp Res 2005 Jan;29(1):53-57. [Medline: 15654291]

27. Health Promotion Administration, Ministry of Health and Welfare. Fagerstrom Tolerance Questionnaire. URL: http:/ /health99.hpa.gov.tw/OnlinkHealth/Quiz nicotine.aspx [accessed 2018-05-21] [WebCite Cache ID 6zaIKv7d2]

28. Li RH, Ho MC, Tang TC, Chang CFT. Development of the Betel Nut Dependency Scale (BNDS). Chinese J Psychol 2012;54:331-348. [doi: 10.6129/CJP.2012.5403.04]

29. Babor TF, Higgins-Biddle JC, Saunders JB, Monteiro MG. AUDIT-The alcohol use disorders identification test: a guideline for use in primary care. Geneva: World Health Organization; 2001.

30. Fagerstrom KO, Schneider NG. Measuring nicotine dependence: a review of the Fagerstrom Tolerance Questionnaire. J Behav Med 1989 Apr;12(2):159-182. [Medline: 2668531]

31. Pomerleau CS, Carton SM, Lutzke ML, Flessland KA, Pomerleau OF. Reliability of the Fagerstrom Tolerance Questionnaire and the Fagerstrom Test for Nicotine Dependence. Addict Behav 1994;19(1):33-39. [Medline: $\underline{8197891]}$

32. Huang CL. The Comprehensive Cigarette Dependence Scale: Development and Psychometric Evaluation [unpublished doctoral dissertation]. Kaohsiung: Kaohsiung Medical University; 2008.

33. Sewo Sampaio PY, Sampaio RA, Yamada M, Arai H. Systematic review of the Kihon Checklist: Is it a reliable assessment of frailty? Geriatr Gerontol Int 2016 Aug;16(8):893-902. [doi: 10.1111/ggi.12833] [Medline: 27444395]

34. World Health Organization. WHO global report on trends in tobacco smoking 2000-2025. URL: http://www.who.int/ tobacco/publications/surveillance/reportontrendstobaccosmoking/en/index4.html [accessed 2018-05-20] [WebCite Cache ID 6zYSaVmqT]

35. Roche AM, Freeman T, Skinner N. From data to evidence, to action: findings from a systematic review of hospital screening studies for high risk alcohol consumption. Drug Alcohol Depend 2006 Jun 09;83(1):1-14. [doi: 10.1016/j.drugalcdep.2005.10.011] [Medline: 16310323]

36. Rosón B, Monte R, Gamallo R, Puerta R, Zapatero A, Fernández-Solá J, ASMI Study Group. Prevalence and routine assessment of unhealthy alcohol use in hospitalized patients. Eur J Intern Med 2010 Oct;21(5):458-464. [doi: 10.1016/j.ejim.2010.04.006] [Medline: 20816605]

37. Tsai YF, Chen CY, Lin YP, Tsai MC, Weng CE. Hazardous drinking problems in family members of problem-drinker patients in Chinese general hospitals. Gen Hosp Psychiatry 2012;34(6):633-638. [doi: 10.1016/j.genhosppsych.2012.06.003] [Medline: 22771107]

38. Rojas JI, Nisbet RB. Detecting alcohol use disorders in primary care settings. J Okla State Med Assoc 2011 Jan;104(1):23-27. [Medline: 21446301]

\author{
Abbreviations \\ AUDIT: Alcohol Use Disorders Identification Test \\ BNDS: Betel Nut Dependency Scale \\ C-AUDIT: Chinese-version Alcohol Use Disorders Identification Test \\ C-FTQ: Chinese-version Fagerstrom Tolerance Questionnaire \\ FTQ: Fagerstrom Tolerance Questionnaire \\ RA: research assistant \\ WHO: World Health Organization
}

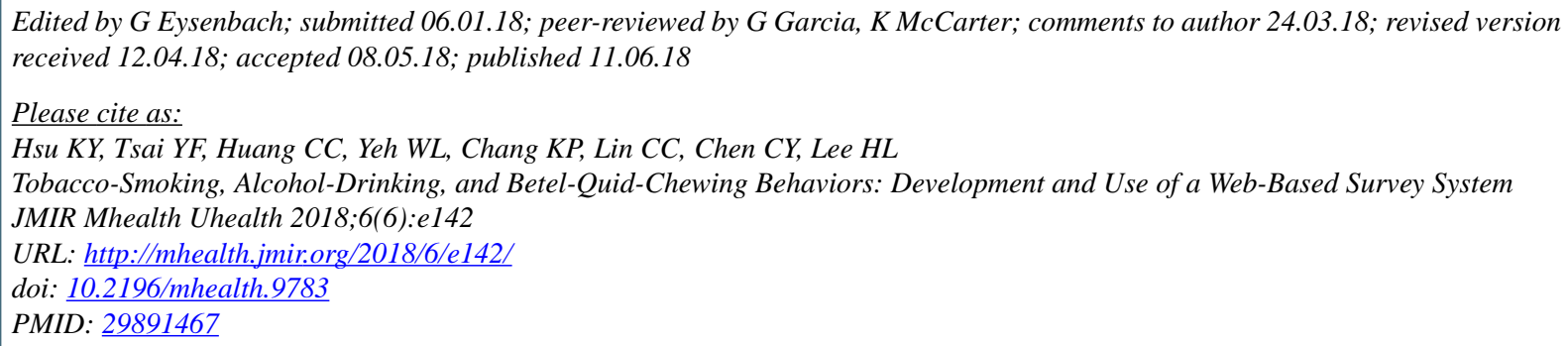


(CKuo-Yao Hsu, Yun-Fang Tsai, Chu-Ching Huang, Wen-Ling Yeh, Kai-Ping Chang, Chen-Chun Lin, Ching-Yen Chen, Hsiu-Lan Lee. Originally published in JMIR Mhealth and Uhealth (http://mhealth.jmir.org), 11.06.2018. This is an open-access article distributed under the terms of the Creative Commons Attribution License (https://creativecommons.org/licenses/by/4.0/), which permits unrestricted use, distribution, and reproduction in any medium, provided the original work, first published in JMIR mhealth and uhealth, is properly cited. The complete bibliographic information, a link to the original publication on http://mhealth.jmir.org/, as well as this copyright and license information must be included. 